\title{
Patient preference in psychological treatment and associations with self- reported outcome: national cross-sectional survey in England and Wales
}

Ryan Williams ${ }^{1}$, Lorna Farquharson ${ }^{2,3}$, Lucy Palmer², Paul Bassett ${ }^{4}$, Jeremy Clarke ${ }^{3}$, David M. Clark ${ }^{5}$ and Mike J. Crawford ${ }^{1,3^{*}}$

\begin{abstract}
Background: Providers of psychological therapies are encouraged to offer patients choice about their treatment, but there is very little information about what preferences people have or the impact that meeting these has on treatment outcomes.

Method: Cross-sectional survey of people receiving psychological treatment from $184 \mathrm{NHS}$ services in England and Wales. 14,587 respondents were asked about treatment preferences and the extent to which these were met by their service. They were also asked to rate the extent to which therapy helped them cope with their difficulties.

Results: Most patients (12,549-86.0 \%, 95 \% Cl: 85.5-86.6) expressed a preference for at least one aspect of their treatment. Of these, 4,600 (36.7\%, $95 \%$ Cl: 35.8-37.5) had at least one preference that was not met. While most patients reported that their preference for appointment times, venue and type of treatment were met, only 1,769 (40.5\%) of the 4,253 that had a preference for gender had it met. People who expressed a preference that was not met reported poorer outcomes than those with a preference that was met (Odds Ratios: appointment times $=0.29$, venue $=0.32$, treatment type $=0.16$, therapist gender $=0.32$, language in which treatment was delivered $=0.40$ ) .
\end{abstract}

Conclusions: Most patients who took part in this survey had preferences about their treatment. People who reported preferences that were not met were less likely to state that treatment had helped them with their problems. Routinely assessing and meeting patient preferences may improve the outcomes of psychological treatment.

Keywords: Psychological treatment, Choice behaviour, Patient preference, Psychotherapy, Treatment outcome

\section{Background}

It has been argued that increasing the amount of choice that patients have can encourage them to take greater interest in their health, increase their adherence to treatment and ensure more cost effective use of available resources [1]. In England efforts to increase patient choice are seen as central to delivering patientcentred care [2], and a number of steps have been

\footnotetext{
* Correspondence: m.crawford@imperial.ac.uk

${ }^{1}$ Imperial College London, London, UK

${ }^{3}$ College Centre for Quality Improvement, Royal College of Psychiatrists, 21

Prescot Street, E1 8BB London, UK

Full list of author information is available at the end of the article
}

taken to give patients greater choice about when and where they are treated [3].

Surveys of patients suggest that many would like greater choice of treatment [4]. Evidence to support claims that providing greater choice to patients increases service quality is limited [5]. While some studies have shown that interventions which support people to make choices about treatment options lead to improved health $[6,7]$ others have not [8].

Multiple guidelines on the application of evidencebased practise emphasise the use of patient preferences to direct treatment selection, considering it of equal value to symptom profiles, resource availability or past 
treatment history in guiding management $[9,10]$ Others speculate that understanding patient preference may improve provider-patient communication, encourage patients to engage with treatment and improve adherence $[11,12]$.

Much of the literature examining the effect of patient choice on clinical outcomes in mental health focuses on selection between psychological and pharmacological treatment, and yields varied results. Some studies indicate that receiving preferred treatment conveys an additional benefit in terms of clinical measures and treatment retention $[13,14]$ as well as cost-effectiveness [15], while others find no effect $[16,17]$. These contrasting findings may be due to the reluctance of patients with strong preferences to enter controlled trials where they could be randomised to treatment, even those with partial-preference designs $[18,19]$.

Within the specific context of psychological treatment, patient choice may exert a significant influence due to the large number of variables involved compared with pharmacological interventions. Variations in time, place or therapist, as well as differing modes of psychological therapy, could all affect the therapeutic value of treatment for a specific patient. Meeting patient preferences for some aspects of psychological therapy may lead to lower dropout rates $[18,20]$. However, at this stage very little is known about the preferences that people referred for psychological therapy have or the impact that meeting these preferences has on patient-reported outcomes.

The National Audit of Psychological Therapies for Anxiety and Depression was a large scale examination of the practice of psychological therapies in England and Wales [21]. The audit comprised an examination of routine clinical records and a survey of people using a wide range of state-funded primary and secondary care services and compared clinical outcomes and patient experience against agreed standards of care.

The audit was commissioned by the Healthcare Quality Improvement Partnership as part of the National Clinical Audit and Patient Outcomes Programme. The second round of the audit was conducted in 2012-13. At the request of service user representatives on the Project Advisory Group, we added a series of questions on patient preferences to the survey. We analysed data from the audit to determine the prevalence of patient preferences, and the proportion of people who felt that these had been met. We set out to determine the extent to which patients have preferences for psychological treatments and explore what, if any, impact responding to these preferences has on their experiences of treatment.

\section{Method}

All audit data were collected during the second round of the National Audit of Psychological Therapies. A detailed account of methods used in the audit have been published elsewhere [21]. We identified the sample for the audit by contacting medical directors and chief executives of NHS Trusts in England and Head Boards in Wales and asking them to submit contact details for the psychological treatment services they provide. We combined these with contact details from a register of Improving Access to Psychological Therapies services in England, and services that participated in the earlier round of the audit [22]. Prior to the start of the audit we were advised by the National Research Ethics Service and the Ethics and Confidentiality Committee of the $\mathrm{Na}$ tional Information Governance Board that formal ethical approval was not required for this quality improvement initiative.

220 services took part in the audit (approximately 60 $\%$ of the 350 to 380 services which we estimate were eligible to take part at that time). Each service selected a census date within the period $1^{\text {st }}$ July- $31^{\text {st }}$ October 2012 and all patients receiving treatment from the service on this date were invited to complete an anonymous survey that examined their experience of treatment. Patients were given written information about the audit and had the option of completing either a paper or a web-based version of the questionnaire. Those who opted to complete a paper version were given a pre-paid envelope to return the questionnaire directly to the audit team. In an effort to minimise response bias we made it clear to each participant that the survey was confidential and that the feedback they have could not be traced back to them. We did not seek written informed consent to take part in the survey. Consent was implied when a patient responded to the survey.

Demographic data were not collected from people who did not participate in the survey, but were available from a parallel audit of clinical records that was conducted at the same time.

\section{Main outcome measure and covariates}

The questionnaire for the survey was developed in collaboration with users and providers of psychological treatment services and was piloted prior to the main audit to check that items were understandable and acceptable. For our main outcome measure, respondents were asked to indicate the extent to which they agreed with the statement 'this talking treatment helps me cope with my difficulties' using a five-point scale (strongly agree, agree, not sure, disagree, strongly disagree).

Patients were also asked five questions about preferences for treatment and whether these preferences had been met. Respondents were asked about preferences about the venue where treatment was delivered, the time of day of appointments, gender of the therapist that they saw, language in which the treatment was delivered (or 
access to help from an interpreter), and the type of therapy. For each of these features of treatment, respondents were asked to indicate whether it was "not important to me- I have no strong preference", it was "important to me and I was given enough choice", it was "important to me but I was not given enough choice" or I am "unsure". Finally respondents were asked to indicate their age, gender, sexual orientation and ethnicity from a range of categorical options. A full copy of the questionnaire used in the patient survey can be downloaded at:

www.rcpsych.ac.uk/workinpsychiatry/qualityimprovement/nationalclinicalaudits/psychologicaltherapies/psychologicaltherapies/secondroundresources.aspx.

\section{Statistical methods}

We started by calculating the proportion of respondents who had preferences for each of the five items, and whether, among those that had a preference, respondents felt that they were offered enough choice. Data from those who indicated that they were 'unsure' were added to those who expressed no preference as we judged that such people were unlikely to have a strong preference.

We then examined univariate associations between whether patients had a preference for the five choice items and demographic characteristics (age, gender, ethnicity and sexual orientation). Finally, we examined associations between whether people felt their treatment had helped them cope with their difficulties (main outcome) and the five choice variables. For this analysis we converted responses on the five-point scale to a dichotomous variable, according to whether patients agreed/ strongly agreed that treatment had helped them cope with their difficulties or were not sure/ disagreed/ strongly disagreed.

A feature of the data were that patients were clustered within different services. Outcomes from patients from the same service may be more similar than outcomes from patients from different services. Therefore, to allow for this data structure, all analyses were performed using multilevel statistical methods. Two level models were used with patients nested within services. Due to the binary nature of the outcome, the analysis was performed using multilevel logistic regression. Initially the association between each choice variable and the outcome was examined without considering any possible confounding variables. Subsequently the analysis was repeated, adjusting for demographic variables found to be associated with the choice variables.

\section{Results}

Of 220 psychological therapy services that took part in the audit, 184 (83.6\%) collected data for the patient survey. Patient questionnaires were sent out to 76,950 people and 15,078 (19.6 \%) responded. Incomplete returns were removed and data from 14,587(19.0 \%) were included in this analysis. Characteristics of those who took part in the study are presented in Table 1 together with aggregate data from the audit of clinical records of people using the 220 treatment services during this period. People who responded to the survey were more likely to be white, female and older than nonresponders.

Overall, $86.0 \%$ of patients expressed a preference for at least one aspect of their therapy $(n=12549,95 \% \mathrm{CI}$ : 85.5-86.6). $31.5 \%$ of patients expressed at least one preference and felt that they had not been offered sufficient choice $(n=4600,95 \%$ CI: 30.8-32.3). These accounted for $36.7 \%$ of those that expressed at least one preference (95 \% CI: 35.8-37.5).

Frequencies and proportion of patients who expressed preferences for each of the five choice variables are presented in Table 2 below. Patients were most likely to have a preference for time of day for their sessions (72.6 $\%$ ) and least likely to have a preference for accessing therapy in a language other than English or through an interpreter $(8.0 \%)$. For each variable, most people who had a preference felt they were offered enough choice, aside from the 4,252 patients who had a preference for the gender of their therapist, of whom 2483 (58.4\%) felt they were not offered enough choice. Demographic factors associated with the likelihood of expressing preferences, taking account of clustering by service are presented in Table 3.

Associations between choice variables and patient reported outcomes are presented in Table 4. Patients who reported that they were not given adequate choice were less likely to agree that their treatment helped them cope with their difficulties. Differences between those who had preferences that were met and those with no preferences were less marked aside from for type of therapy and time of day: those reporting that these preferences were met, were more likely to report that therapy had helped them with their problems.

\section{Discussion}

Data from this survey suggest that three quarters of people who are referred to psychological therapy services for common mental health problems have a preference for when therapy is delivered, and around half have a preference for where and what type of therapy. A significant minority of people have preferences for the gender of the therapist and the language that therapy is delivered in.

The likelihood of patients expressing preferences varies according to demographic factors. As might be expected, patients from certain ethnic groups are more likely to report that accessing therapy in another 
Table 1 Demographic characteristics of study participants and comparative data from the case note audit

\begin{tabular}{|c|c|c|c|}
\hline Demographic characteristics & Study sample n (\%) & Sample included in the case notes audit $\mathrm{n}(\%)$ & Difference in proportions $(95 \% \mathrm{Cl})$ \\
\hline Age & $N=14148$ & $N=122740$ & \\
\hline $18-24$ & $1088(7.69)$ & 16405 (13.37) & $-5.68(-5.18,-6.15)$ \\
\hline $25-34$ & $2513(17.76)$ & $30117(24.54)$ & $-6.78(-6.09,-7.44)$ \\
\hline $35-44$ & $3287(23.23)$ & $28796(23.46)$ & $-0.23(-0.51,0.96)$ \\
\hline $45-54$ & $3519(24.87)$ & $25359(20.66)$ & $2.57(1.84,3.31)$ \\
\hline $55-64$ & $2474(17.49)$ & $14269(11.63)$ & $5.86(5.22,6.53)$ \\
\hline $65-74$ & $980(6.93)$ & $5617(4.58)$ & $2.35(1.92,2.90)$ \\
\hline $75+$ & $287(2.03)$ & $2177(1.77)$ & $0.25(0.02,0.51)$ \\
\hline Gender & $N=13954$ & $N=122585$ & \\
\hline Female & $9656(69.24)$ & $79157(64.57)$ & $4.63(3.81,5.43)$ \\
\hline Male & $4298(30.76)$ & $43428(35.43)$ & - \\
\hline Ethnicity & $N=14004$ & $N=101550$ & \\
\hline White & 13134 (93.79) & 90769 (89.38) & $4.41(3.95,4.84)$ \\
\hline Asian & $348(2.48)$ & 3736 (3.68) & $-1.19(-0.9,-1.47)$ \\
\hline Black & 159 (1.14) & 2788 (2.75) & $-1.61(-1.40,-1.80)$ \\
\hline Mixed & $219(1.56)$ & $2181(2.15)$ & $-0.58(-0.35,-0.80)$ \\
\hline Chinese/Other & $144(1.03)$ & 2078 (2.05) & $-1.02(-0.81,-1.20)$ \\
\hline
\end{tabular}

language or through an interpreter is important to them. Specific ethnic groups (Asian or Mixed) were also more likely to express preferences about the gender of their therapist. Patients who report a sexual orientation other than heterosexual were more likely to express preferences about their therapist's gender, and about the type of therapy they receive, while women are more likely than men to express preferences about all components of their therapy other than language.

Of those patients who expressed preferences, the majority stated that they were offered adequate choice about this component of their therapy. However, a significant proportion reported that they were not given adequate choice. The exact proportion varied according to the aspect of therapy such that around one in five who had a preference for the time of day felt that this had not been met $(17.5 \%, n=1837)$ compared to around a third of those who expressed preferences for venue $(29.8$
$\%, n=2242)$, type of therapy $(32.9 \%, n=2441)$ or language $(37.3 \%, n=382)$. The preference that was least likely to be met was gender of therapist for which only 1,769 (41.6\%) felt their choice had been met.

The value of providing patients with adequate choice when they express a preference is supported by the findings for patients' ratings of the extent to which they considered therapy had helped them overcome their problems. Patients who expressed preferences and were not offered adequate choices were less likely to agree that their therapy had helped them, regardless of the component they held preferences for. The size of this effect varies by component- patients who had preferences for type of therapy and were not offered adequate choice were around 6 times less likely to agree that they had been helped than those who were (OR 0.16, 95 \% CI 0.14-0.18). Patients who were not offered choices for other components were around 2-3 times less likely, e.g.

Table 2 Proportion of patients expressing preferences for choice of components of psychological treatment

\begin{tabular}{|c|c|c|c|}
\hline \multirow[t]{3}{*}{ Aspect of treatment } & \multirow{3}{*}{$\begin{array}{l}\text { No preference } \\
\text { n \% (95\% Cl) }\end{array}$} & \multicolumn{2}{|l|}{ Expressed a preference } \\
\hline & & Given adequate choice & Not given adequate choice \\
\hline & & n \% (95 \% Cl) & n \% (95 \% Cl) \\
\hline Choice of venue & $685547.7(46.9-48.5)$ & $528236.7(35.9-37.5)$ & $224215.6(15.0-16.2)$ \\
\hline Time of day of appointments & $395027.4(26.7-28.1)$ & $863959.9(59.1-60.7)$ & $183712.7(12.2-13.2)$ \\
\hline Gender of therapist & $1002770.2(69.5-71.0)$ & $176911.9(11.4-12.4)$ & $248317.9(16.8-18.0)$ \\
\hline Language/ interpreter & $1174392.0(91.5-92.5)$ & $6434.9(4.5-5.3)$ & $3823.1(2.8-3.4)$ \\
\hline Type of treatment & $684448.0(47.2-48.8)$ & 498134.9 (34.1-35.7) & 244117.1 (16.5-17.7) \\
\hline
\end{tabular}


Table 3 Characteristics of patients who expressed a preference for choosing aspects of their psychological treatment (adjusted for clustering by service)

\begin{tabular}{|c|c|c|c|c|c|c|}
\hline \multicolumn{2}{|c|}{ Patient characteristic } & $\begin{array}{l}\text { Preference for } \\
\text { choice of venue } \\
\text { OR ( } 95 \% \text { Cl) }\end{array}$ & $\begin{array}{l}\text { Preference for time } \\
\text { of appointments } \\
\text { OR (95\% Cl) }\end{array}$ & $\begin{array}{l}\text { Preference for } \\
\text { gender of therapist } \\
\text { OR (95\% Cl) }\end{array}$ & $\begin{array}{l}\text { Preference for } \\
\text { language/interpreter } \\
\text { OR (95\% Cl) }\end{array}$ & $\begin{array}{l}\text { Preference for } \\
\text { type of therapy } \\
\text { OR }(95 \% \mathrm{Cl})\end{array}$ \\
\hline \multirow{8}{*}{ Age } & & & & & & \\
\hline & $18-24$ & Reference & Reference & Reference & Reference & Reference \\
\hline & $25-34$ & $1.07(0.93-1.23)$ & $1.31(1.10-1.54)^{*}$ & $0.80(0.69-0.93)^{*}$ & $1.06(0.79-1.42)$ & $1.16(1.01-1.34)^{*}$ \\
\hline & $35-44$ & $1.13(0.99-1.30)$ & $1.08(0.92-1.26)$ & $0.76(0.65-0.88)^{* *}$ & $1.12(0.84-1.49)$ & $1.02(0.89-1.17)$ \\
\hline & $45-54$ & $1.11(0.97-1.27)$ & $0.90(0.77-1.05)$ & $0.83(0.72-0.96)^{*}$ & $1.38(1.05-1.83)^{*}$ & $1.03(0.89-1.18)$ \\
\hline & $55-64$ & $1.18(1.02-1.36)^{*}$ & $0.67(0.57-0.79)^{* *}$ & $0.75(0.64-0.87)^{* *}$ & $1.48(1.11-1.98)^{*}$ & $0.83(0.72-0.96)^{*}$ \\
\hline & $65-74$ & $1.18(0.99-1.40)$ & $0.47(0.39-0.57)^{* *}$ & $0.74(0.62-0.90)^{*}$ & $1.76(1.25-2.47)^{* *}$ & $0.67(0.56-0.80)^{* *}$ \\
\hline & $75+$ & $0.97(0.75-1.25)$ & $0.40(0.31-0.53)^{* *}$ & $0.54(0.40-0.73)^{* *}$ & $1.71(1.02-2.86)^{*}$ & $0.41(0.31-0.54)^{* *}$ \\
\hline \multirow[t]{2}{*}{ Gender } & Male & Reference & Reference & Reference & Reference & Reference \\
\hline & Female & $1.46(1.36-1.57)^{* *}$ & $1.79(1.65-1.93)^{* *}$ & $1.70(1.56-1.85)^{* *}$ & $1.05(0.91-1.20)$ & $1.37(1.27-1.47)^{* *}$ \\
\hline \multirow[t]{3}{*}{ Sexuality } & Heterosexual & Reference & Reference & Reference & Reference & Reference \\
\hline & Gay/Lesbian & $0.89(0.72-1.10)$ & $0.90(0.72-1.13)$ & $1.42(1.14-1.76)^{* *}$ & $0.61(0.37-1.00)$ & $1.31(1.07-1.63)^{*}$ \\
\hline & Bisexual/Other & $0.90(0.72-1.13)$ & $0.90(0.71-1.15)$ & $1.40(1.11-1.76)^{* *}$ & $1.03(0.67-1.58)$ & $1.28(1.02-1.60)^{*}$ \\
\hline \multirow[t]{5}{*}{ Ethnicity } & White & Reference & Reference & Reference & Reference & Reference \\
\hline & Asian & $1.22(0.99-1.51)^{*}$ & $1.40(1.08-1.80)^{*}$ & $1.52(1.22-1.88)^{* *}$ & $3.68(2.83-4.77)^{* *}$ & $1.06(0.86-1.30)$ \\
\hline & Black & $1.05(0.77-1.43)$ & $1.43(0.98-2.09)$ & $1.39(1.01-1.92)$ & $1.53(0.91-2.58)$ & $0.98(0.72-1.34)$ \\
\hline & Mixed & $1.16(0.89-1.51)$ & $1.21(0.89-1.65)$ & $1.45(1.10-1.91)^{*}$ & $0.95(0.55-1.64)$ & $1.29(0.98-1.68)$ \\
\hline & Other & $1.24(0.89-1.72)$ & $1.27(0.86-1.87)$ & $1.37(0.97-1.93)$ & $5.44(3.76-7.85)^{* *}$ & $1.69(1.19-2.38)^{*}$ \\
\hline
\end{tabular}

Note: ${ }^{*} p<0.05,{ }^{* *} p<0.01$ for differences compared to the reference group

Table 4 Proportion of patients who believed treatment had helped them cope with their difficulties according to whether preferences for choice were met

\begin{tabular}{|c|c|c|c|c|}
\hline Aspect of treatment & Preference & $\mathrm{n} / \mathrm{N}(\%)$ & Odds Ratio (95 \% Cl) & $p$-value \\
\hline \multirow[t]{3}{*}{ Choice of venue } & No preference & $5769 / 6776(85 \%)$ & - & \multirow[t]{3}{*}{$<0.001$} \\
\hline & Got preference & 4507/5214 (86 \%) & $1.07(0.95-1.19)$ & \\
\hline & Did not & 1491/2218 (67 \%) & $0.35(0.31-0.39)$ & \\
\hline \multirow[t]{3}{*}{ Time of day of appointments } & No preference & 3248/3895 (83 \%) & - & \multirow[t]{3}{*}{$<0.001$} \\
\hline & Got preference & 7377/8541 (86 \%) & $1.22(1.09-1.36)$ & \\
\hline & Did not & 1177/1819 (65 \%) & $0.37(0.32-0.42)$ & \\
\hline \multirow[t]{3}{*}{ Gender of therapist } & No preference & 8492/9918 (86 \%) & - & \multirow[t]{3}{*}{$<0.001$} \\
\hline & Got preference & 1519/1742 (87 \%) & $1.09(0.92-1.28)$ & \\
\hline & Did not & 1682/2461 (68 \%) & $0.36(0.32-0.40)$ & \\
\hline \multirow[t]{3}{*}{ Language/ interpreter } & No preference & 9673/11629 (83 \%) & - & \multirow[t]{3}{*}{$<0.001$} \\
\hline & Got preference & 538/638 (84 \%) & $1.07(0.85-1.34)$ & \\
\hline & Did not & 258/378 (68 \%) & $0.45(0.36-0.56)$ & \\
\hline \multirow[t]{3}{*}{ Type of treatment } & No preference & $5762 / 6768(85 \%)$ & - & \multirow[t]{3}{*}{$<0.001$} \\
\hline & Got preference & 4466/4926 (91\%) & $1.63(1.44-1.84)$ & \\
\hline & Did not & $1452 / 2416(60 \%)$ & $0.26(0.23-0.29)$ & \\
\hline
\end{tabular}


venue (OR 0.32, $95 \%$ CI 0.29-0.36), time of day (OR $0.29,95 \%$ CI 0.26-0.32), therapist gender (OR 0.32, 95 $\%$ CI 0.27-0.37), language (OR 0.40, 95 \% CI 0.30-0.54).

Even more strikingly, for some components (time of day and type of therapy), patients who expressed preferences and received adequate choices were more likely to agree that their therapy had helped than patients with no preferences at all eg. type of therapy (OR 1.69, $95 \%$ CI 1.51-1.91), time of day (OR 1.26, 95 \% CI 1.14-1.40).

\section{Strengths and limitations of the study}

Data were obtained from a large, heterogeneous sample of patients from across the whole of England and Wales. Participants were recruited from a variety of services providing differing treatment modalities, incorporating a variety of settings. The outcome measures used were derived from feedback from an expert group of service users and providers. However the study also has several important limitations which must be taken into consideration when interpreting the findings.

Comparative data from a case notes audit conducted in parallel with the survey suggests that the response rate may have been different in different groups of patients [23]. It is possible that people who took time to respond to the survey were more or less likely to have preferences about treatment than those who did not respond. While caution therefore needs to be taken in generalising data on patient preferences to all those using psychological services, the poor response rate is in itself unlikely to affect associations between whether preferences were met and self-reported outcomes.

The study also relied entirely on quantitative data obtained through self-report measures. Other methods, such as qualitative interviews with patients and psychological therapists, may have allowed us to gain more detailed information on the nature of preferences, how they were expressed, reasons why they may not have been met and the possible impact lack of choice may have had on the person's experience of therapy.

We did not request information about the specific types of therapies that patients preferred when they expected a preference for this aspect of treatment. Three quarters of the respondents were from services funded through the 'Improving Access to Psychological Therapies' programme which delivers treatment according to a stepped care model. For these respondents, not being given adequate choice could refer to not being able to choose between low intensity therapy (such as guided self-help) and a traditional high intensity (face-to-face) therapy, or it could refer to not being able to choose between different high intensity therapies.

As the data are cross-sectional we are unable to explore the nature of the association between preferences for treatment and self-reported outcomes. While it is possible that people who had preferences for treatment that were not met went on to experience less benefit from treatment, it is also possible that people who had a poor experience of treatment were more likely to attribute this to their initial preferences not being met when they completed the survey.

Finally, no information is available about diagnoses or other clinical details, and the study was reliant on patient recall of information.

\section{Implications}

Many agencies that have produced guidelines for the treatment of mental illness already stress the importance of understanding patient preferences for treatment options, and where possible using these preferences to guide management decisions [24, 25]. This trend has emerged despite a lack of compelling evidence about whether eliciting and meeting patient preference has an impact on treatment outcomes [26, 27]. Data from this survey suggest that, in relation to the provision of psychological therapies for common mental health problems, efforts to meet patient preferences may have an influence on whether people feel that treatment helps them.

To be successful, psychological therapies require a greater degree of active involvement from patients compared to most other types of pharmacological and medical treatment. They are time consuming, patients must travel regularly to a specific location, and they require patients to form a therapeutic relationship with a therapist [28]. However, no guidance currently exists to indicate how much choice patients should be offered over the conditions and setting of their therapy. Our finding that those who are not offered adequate choices are less likely to agree that their treatment has helped them, highlights the importance of eliciting patient preference in the context of psychological therapy, and where possible offering a choice of options in response.

Our results also imply that particular effort should be made to explore preferences relating to time of day and type of psychological therapy, as offering adequate choice to those with preferences may confer added benefit over those with no preferences. Out of the range of components that we examined, these were also the two where it may be easiest to offer people different options.

In England, the Improving Access to Psychological Therapies (IAPT) initiative has laid out clear guidance for psychological therapy services regarding providing choice of venue, time of appointment, therapist and type of therapy [29] and expects this to be implemented across the UK [30, 31]. At present, the accreditation programme for psychological therapies looks at how these recommendations are being met when services apply for accreditation [32]. The national audit also 
made recommendations for services to help improve the choice that they offer to patients [21]. At an individual level, prior authors have suggested techniques for addressing patient preferences in psychotherapy [33].

More research is needed to explore the long-term effects of patient choice in psychological therapy. It is difficult to envisage how controlled trials could be devised in which people are randomised to receive or be denied choice of time, place or other aspects of therapy. However prospective observational studies of patients attending different types of services, where more or less choice is available, would be possible and have been recommended as a valuable alternative to randomised controlled trials in these circumstances [34]. These may provide a better guide to the impact that meeting patient preferences have on treatment outcomes. While patient accounts of the impact of therapy are important, such studies should also include standardised outcome measures of mental health.

\section{Conclusions}

This study provides data on the proportion of patients that have preferences for different aspects of the psychological therapy they are offered. The majority of patients would like at least one component of their therapy to be tailored according to their preference. A significant subgroup of these patients feel that they are not offered an adequate range of choice over such elements of their therapy, and that their preferences are not accommodated by their healthcare provider.

We also found that there were demographic differences in the expression of patient preferences and that patients who hold preferences which are not met, are less likely to report that their treatment was helpful. Whilst we are unable to infer a causative relationship between meeting preferences and outcomes, the association between them emphasises the need for further research in this area. We would suggest that any future investigations prospectively examine the impact that failure to both elicit, and respond to, patients' preferences has on the efficacy of psychological treatments. Such investigations should ideally employ clinical outcome measures, as well as monitoring rates of attendance and attrition.

\section{Competing interests}

The authors declare that they have no competing interests.

\section{Authors' contributions}

RW contributed to the design of the study, conducted the analysis of study data and prepared the first draft of the manuscript. LF contributed to the design of the study and the preparation of the final version of the manuscript. LP contributed to the design of the study, oversaw data collection and contributed to the preparation of the final version of the manuscript. PB conducted the analysis plan, conducted the multilevel analysis and prepared the first draft of the contributed to the design of the study and the preparation of the final version of the manuscript. JC contributed to the design of the study and preparation of the final version of the manuscript. DC contributed to the plans for data analysis and preparing the final version of the manuscript. MC designed of the study, oversaw the analysis and the preparation of the manuscript. All authors read and approved the final manuscript.

\section{Acknowledgments}

The audit was funded by NHS England and the Welsh Government. The views expressed in this publication are those of the authors and not necessarily those of the funder. The National Audit of Psychological Therapies (NAPT) is managed by the Royal College of Psychiatrists' College Centre for Quality Improvement (CCQI). It is commissioned by the Healthcare Quality Improvement Partnership (HQIP) as part of the National Clinical Audit and Patient Outcomes Programme (NCAPOP).

\section{Author details}

${ }^{1}$ Imperial College London, London, UK. ${ }^{2}$ Royal Holloway, University of London, London, UK. ${ }^{3}$ College Centre for Quality Improvement, Royal College of Psychiatrists, 21 Prescot Street, E1 8BB London, UK. ${ }^{4}$ Stats Consultancy, Amersham, UK. ${ }^{5}$ University of Oxford, Oxford, UK.

Received: 30 June 2015 Accepted: 14 December 2015

Published online: 15 January 2016

\section{References}

1. Wanless D. Securing our future health: Taking a long-term view. London: Her Majesty's Treasury; 2002.

2. Department of Health. Creating a Patient Led NHS: Delivering the NHS Improvement Plan. Department of Health. 2005.

3. Department of Health. 2014/2015 Choice Framework. Department of Health. 2014.

4. Coulter A. Do patients want a choice and does it work? Br Med J. 2010;341:c4989. doi:10.1136/bmj.c4989.

5. Fotaki M, Roland M, Boyd A, McDonald R, Scheaff R, Smith L. What benefits will choice bring to patients? Literature review and assessment of implications. J Health Serv Res Policy. 2008;13(3):178-84. doi:10.1258/jhsrp. 2008.007163.

6. Greenfield S, Kaplan SH Jr WJ, Yano EM HJF. Patients' participation in medical care: effects on blood sugar control and quality of life in diabetes. J Gen Intern Med. 1988;3:448-57.

7. Clark NM, Janz NK, Dodge JA, Mosca L, Lin X, Long Q, et al. The effect of patient choice of intervention on health outcomes. Contemp Clin Trials. 2008;29:679-86. doi:10.1016/j.cct.2008.04.002. Epub 2008 Apr 20.

8. Kawamoto K, Houlihan CA, Balas EA, Lobach DF. Improving clinical practice using clinical decision support systems: a systematic review of trials to identify features critical to success. Br Med J. 2005;330(7494):765.

9. Papakostas Gl. Initial treatment approaches for patients with major depressive disorder. J Clin Psychiatry. 2009;70(6), e18.

10. McHugh RK, Whitton SW, Peckham AD, Welge JA, Otto MW. Patient preference for psychological vs pharmacologic treatment of psychiatric disorders: a meta-analytic review. J Clin Psychiatry. 2013;74(6):595-602.

11. Narasimhan M, Raynor JD, Jones AB. Depression in the medically ill: diagnostic and therapeutic implications. Curr Psychiatry Rep. 2008;10(3):272-9.

12. Houle J, Villaggi B, Beaulieu MD, Lespérance F, Rondeau G, Lambert J. Treatment preferences in patients with first episode depression. J Affect Disord. 2013;147(1-3):94-100.

13. Chilvers C, Dewey M, Fielding K, Gretton V, Miller P, Palmer B, et al. Counselling versus Antidepressants in Primary Care Study Group. Antidepressant drugs and generic counselling for treatment of major depression in primary care: randomised trial with patient preference arms. Br Med J. 2001;322(7289):772-5.

14. Kocsis JH, Leon AC, Markowitz JC, Manber R, Arnow B, Klein DN, et al. Patient preference as a moderator of outcome for chronic forms of major depressive disorder treated with nefazodone, cognitive behavioral analysis system of psychotherapy, or their combination. J Clin Psychiatry. 2009;70(3):354-61.

15. Le QA, Doctor JN, Zoellner LA, Feeny NC. Cost-effectiveness of prolonged exposure therapy versus pharmacotherapy and treatment choice in posttraumatic stress disorder (the Optimizing PTSD Treatment Trial): a doubly randomized preference trial. J Clin Psychiatry. 2014;75(3):222-30.

16. Bedi N, Chilvers C, Churchill R, Dewey M, Duggan C, Fielding K, et al. Assessing effectiveness of treatment of depression in primary care. Partially randomised preference trial. Br J Psychiatry. 2000;177:312-8. 
17. King M, Sibbald B, Ward E, Bower P, Lloyd M, Gabbay M, et al. Randomised controlled trial of non-directive counselling, cognitive-behaviour therapy and usual general practitioner care in the management of depression as well as mixed anxiety and depression in primary care. Health Technol Assess. 2000;4(19):1-83.

18. Swift JK, Callahan JL. The impact of client treatment preferences on outcome: a meta-analysis. J Clin Psychol. 2009;65(4):368-81. doi:10.1002/jclp. 20553.

19. Dunlop BW, Kelley ME, Mletzko TC, Velasquez CM, Craighead WE, Mayberg HS. Depression beliefs, treatment preference, and outcomes in a randomized trial for major depressive disorder. J Psychiatr Res. 2012;46(3):375-81. PubMed PMID: 22118808.

20. Swift JK, Callahan JL, Vollmer BM. Preferences. J Clin Psychol. 2011;67(2):155-65. doi:10.1002/jclp.20759.

21. Royal College of Psychiatrists. Second Round of the National Audit of Psychological Therapies for Anxiety and Depression, National Report 2013. Royal College of Psychiatrists. 2013. Available from: www.rcpsych.ac.uk/napt.

22. Royal College of Psychiatrists. National Audit of Psychological Therapies for Anxiety and Depression, National Report 2011. Royal College of Psychiatrists. 2011. Available from: www.rcpsych.ac.uk/napt.

23. Crawford MJ, Thana L, Farquharson L, Palmer L, Hancock E, Bassett P, Clarke J, Parry GD. Patient experience of negative effects of psychological treatment: results of a national survey in England and Wales. Br J Psychiatry. 2015 (in press).

24. NHS Choices. The NHS Constitution for England. NHS Choices. 2009

25. National Institute for Health and Care Excellence. Psychosis and schizophrenia in adults: treatment and management. NICE. 2014.

26. Dobscha SK, Corson K, Gerrity MS. Depression treatment preferences of VA primary care patients. Psychosomatics. 2007;48(6):482-8.

27. Fotaki M. Is patient choice the future of health care systems? Int J Health Policy Manage. 2013;1(2):121-3.

28. Lambert MJ, Barley DE. Research summary on the therapeutic relationship and psychotherapy outcome. Psychother: Theory, Res, Practice, Training. 2001;38(4):357.

29. Care Services Improvement Partnership. IAPT outline service specification. Department of Health. 2007. http://www.iapt.nhs.uk/silo/files/iapt-outlineservice-specification.pdf.

30. Department of Health. IAPT Statement of Intent. Department of Health. 2008

31. Department of Health. Closing the gap: priorities for essential change in mental health. Department of Health. 2014

32. College Centre for Quality Improvement (Royal College of Psychiatrists) \& British Psychological Society. Accreditation Programme for Psychological Therapies Services. Royal College of Psychiatry Br Psychol Soc. 2015.

33. Tompkins KA, Swift JK, Callahan JL. Working with clients by incorporating their preferences. Psychotherapy. 2013:50(3):279-83.

34. King M, Nazareth I, Lampe F, Bower $\mathrm{P}$, Chandler M, Morou M, et al. Conceptual framework and systematic review of the effects of participants and professionals' preferences in randomised controlled trials. Health Technol Assess. 2005:9(35):1-186.

\section{Submit your next manuscript to BioMed Central and we will help you at every step:}

- We accept pre-submission inquiries

- Our selector tool helps you to find the most relevant journal

- We provide round the clock customer support

- Convenient online submission

- Thorough peer review

- Inclusion in PubMed and all major indexing services

- Maximum visibility for your research

Submit your manuscript at www.biomedcentral.com/submit 